\title{
Violência contra a mulher: o que acontece quando a Delegacia de Defesa da Mulher está fechada?
}

\author{
Violence against women: what happens when the Women's \\ Protection Police Station is closed?
}

Dinair Ferreira Machado (https://orcid.org/0000-0003-3006-7110) ${ }^{1}$

Margareth Aparecida Santini de Almeida (https://orcid.org/0000-0002-4603-2513) ${ }^{1}$

Adriano Dias (https://orcid.org/0000-0001-6895-372X) ${ }^{1}$

João Marcos Bernardes (https://orcid.org/0000-0003-4494-9421) ${ }^{1}$

Elen Rose Lodeiro Castanheira (https://orcid.org/0000-0002-4587-7573) ${ }^{1}$

${ }^{1}$ Faculdade de Medicina de Botucatu, Universidade Estadual Paulista Júlio de Mesquita Filho. AC Rubião Junior, Jardim Santo Inácio (Rubião Junior).

18618-970 Botucatu SP

Brasil.dinair.machado@ unesp.br

\begin{abstract}
The study analyzes the differences among cases of violence against women registered in police reports (PR) at the Women's Protection Police Station (WPPS) during regular working hours, and those registered during after-hours, in a medium-sized city in the inland state of São Paulo, Brazil. This is a cross-sectional study based on data from PRs registered for one year (2013/2014). PRs were differentiated by period of registration, at regular working hours and after-hours (dependent variable). A chi-square test was used to compare groups. In total, 440 PRs were registered, 373 during regular working hours, and 67 during after-hours. Cases of violence registered during after-hours evidenced more significant threats to women's integrity, as shown by the higher number of cases of perpetrators' flagrante delicto, requests for protective measures and greater severity of assaults, such as bruises, need for hospitalization and referral to forensic medicine (IML), which characterize the greater severity of occurrences when WPPS are closed. Thus, women lack a specialized reception service and a full guarantee of rights in periods of highest risk and vulnerability.
\end{abstract}

Key words Violence against women, Criminal justice, Public health
Resumo Este estudo analisa as diferenças entre os casos de violência contra a mulher, formalizados em boletins de ocorrência (BO) na Delegacia de Defesa da Mulher (DDM), durante a rotina dos formalizados nas Delegacias Civis durante os plantões policiais, em um município de médio porte do interior paulista. Trata-se de um estudo transversal, com base nos BOs realizados no período de um ano (2013/2014). As ocorrências foram diferenciadas conforme o periodo em que foram lavrados os BOs, na rotina ou nos plantões, sendo este último tomado como variável dependente. As comparações entre os grupos foram realizadas pelo teste 2. Foram registrados 440 boletins, sendo 373 na rotina e 67 no plantão. As ocorrências realizadas nos plantões apresentaram maior ameaça à integridade da mulher com um maior número de flagrantes do agressor, solicitação de medidas protetivas e gravidade das agressões, como hematomas, hospitalização e encaminhamento ao IML; caracterizando maior gravidade das ocorrências no período em que a DDM está fechada. Deste modo, falta às mulheres um serviço especializado de acolhimento e ampla garantia de direitos nos periodos de maior risco e vulnerabilidade.

Palavras-chave Violência contra a mulher, Justiça criminal, Saúde pública 


\section{Introdução}

A violência contra a mulher se caracteriza como um fenômeno sociocultural com impacto na saúde pública. Avanços significativos foram conquistados no Brasil em relação à proteção das mulheres em situação de violência, como a criação das Delegacias de Defesa da Mulher (DDM). As DDM tornaram possível para a mulher que deseja realizar a denúncia de agressão, ter um local especializado e com equipe técnica multiprofissional para atendê-la. No entanto, alguns entraves, como o horário de funcionamento das DDM, põem em xeque o ideário de proteção das mulheres ${ }^{1,2}$.

No estado de São Paulo, e no Brasil, as DDM não ficam abertas ao público em tempo integral, o que faz com que os casos de violência ocorridos durante a semana após as 18:00 horas e aos sábados, domingos e feriados sejam formalizados em Delegacias Civis e encaminhados para as DDM no próximo dia útil. Esses casos são caracterizados como sendo de plantão. Nas Delegacias Civis, os casos são abordados dentro do conjunto de violências que ocorre no período noturno e de final de semana, sem uma abordagem específica, quer das vítimas, quer de seus familiares e amigos $^{3,4}$.

Foi somente em agosto de 2016, que uma única DDM do estado de São Paulo, a que fora pioneiramente implantada no município de São Paulo em $1985^{4}$, passou a disponibilizar atendimento 24 horas, sete dias na semana. A implantação dessa delegacia foi um marco nas conquistas do movimento feminista, sendo idealizada como um espaço onde as mulheres deveriam ser acolhidas sem sofrer preconceito e sem julgamentos por uma equipe especializada e qualificada. Porém os serviços prestados, até mesmo nas DDM, por muito tempo foram fortemente orientados pela lógica da conciliação do casal, e os problemas considerados de menor poder ofensivo, diminuindo a gravidade e visibilidade da violência contra a mulher ${ }^{4,5}$.

A luta por uma lei específica que punisse o agressor continuou até a promulgação da Lei Maria da Penha em 2006. Essa lei incorporou a modalidade de pena e a competência para julgamento, além da natureza jurídica da ação penal nos crimes de lesão corporal, caracterizando-os, como violência doméstica ${ }^{6,7}$. A lei também incorporou o modelo de abordagem intersetorial para as mulheres em situação de violência, focando na articulação e interação de princípios e diretrizes previstos nas diferentes políticas de: Assistência Social, Saúde e Segurança Pública ${ }^{8}$. Além disso, a lei viabilizou maior rapidez nas medidas emergenciais de proteção, pois, após a instituição, a própria delegada pode solicitar ao juiz o afastamento do agressor, o que anteriormente só poderia ser realizado por intermédio de um advogado $^{6,7}$.

Ao caracterizar a violência doméstica e familiar contra a mulher como sendo toda ação ou omissão que tenha por base o gênero como causa de morte, sofrimento físico, psicológico, dano patrimonial ou moral, a Lei Maria da Penha delimitou este tipo de ação a uma ordem societária baseada na desigualdade de gênero alicerçada pelo patriarcado, em uma relação de exploração e dominação. Desta forma, a lei abrange não somente a punição do agressor como também a proteção das mulheres, por meio da articulação dos diferentes setores, visando a desconstrução da desigualdade de gênero ${ }^{10,11}$.

A partir da promulgação desta lei, as DDM foram fortalecidas enquanto referência e como principal porta de entrada para o acolhimento e atendimento das mulheres. Constituíram-se em espaços não só de formalização de denúncias, mas, também, nos quais as mulheres deveriam ser orientadas sobre seus direitos, terem a garantia das principais medidas de proteção (tais como: medidas protetivas de urgência, exames de corpo delito e prisão do agressor), assim como oferta e a identificação de outras necessidades para acompanhamento em outros pontos da rede ${ }^{6,7}$. Sendo assim, questiona-se o fato das DDM ficarem abertas apenas no período diurno e durante a semana, uma vez que a vulnerabilidade das mulheres a toda forma de violência não se restringe apenas a esses períodos.

Diante do exposto, considera-se que a análise das diferenças entre as ocorrências formalizadas na DDM das da Delegacia Civil amplia o conhecimento das denúncias realizadas fora dos horários de rotina, dando elementos adicionais que permitam o aprimoramento das ações de atenção às situações de violência contra a mulher. Partese do suposto que as DDM são diferencialmente preparadas para ações qualificadas de acolhimento e para o desencadeamento de medidas intersetoriais de atenção integral à mulher em situação de violência, o que justificaria a necessidade das DDM ofertarem atendimento contínuo, incluindo os períodos de plantão.

O presente estudo teve como objetivo analisar as diferenças entre as ocorrências formalizadas por meio de boletins de ocorrência $(\mathrm{BO})$ na DDM (rotina) das realizadas na Delegacia Civil (plantão). 


\section{Métodos}

Esta pesquisa foi realizada em um município de médio porte com população estimada em 141.032 habitantes para o ano de $2016^{12}$, localizado na região centro-sul do estado de São Paulo.

Trata-se de estudo de abordagem quantitativa, transversal com fonte de dados secundários de $\mathrm{BO}$, formalizados na DDM do município durante a rotina ou formalizados no plantão policial da Delegacia Civil e posteriormente encaminhado à DDM. A coleta de dados se deu no período de abril de 2013 a março de 2014.

Foram levantados todos os boletins registrados por mulheres com idade acima de 18 anos e que fizeram pelo menos uma denúncia de violência. Após leitura e análise integral de todos os boletins registrados no período, foram selecionados para este estudo os boletins enquadrados na categoria parceiro íntimo de acordo com os seguintes critérios: a vítima estar em ou ter tido uma relação íntima com o agressor, podendo este estar na condição de marido/companheiro ou ex-marido/ex-companheiro, namorado ou exnamorado.

A formalização da ocorrência foi diferenciada segundo o período e horário do dia em que foram lavrados os BO: rotina (de segunda a sexta no período comercial) e plantão (segunda a sexta a partir das 18 horas e nos finais de semana e feriados), que para fins da análise proposta será considerada como variável dependente.

As informações constantes dos $\mathrm{BO}$ foram coletadas na DDM do município, extraídas por meio de um formulário próprio, elaborado pelas pesquisadoras, baseado nos dados contidos nos boletins de ocorrência. A coleta de dados foi realizada pelas próprias pesquisadoras.

Para analisar as diferenças das características das mulheres que realizaram a denúncia na rotina e no plantão foram selecionadas as seguintes variáveis: idade, cor da pele, escolaridade, estado civil e ter filhos. Para análise das diferenças das ocorrências foram eleitas as seguintes variáveis: ocorrência de flagrante, solicitação de medida protetiva de urgência, forma de condução à DDM, encaminhamento ao IML, necessidade de hospitalização, hematomas aparentes, violência doméstica, violência psicológica, danos patrimoniais, ameaça, violência sexual, lesão corporal, injúria, realização no final de semana e mês de ocorrência. É importante ressaltar que os tipos de violência são informações preenchidas nos boletins de ocorrência de acordo com a classificação padrão utilizada pelos escrivães nas delegacias.
Deste modo, quando utilizada a classificação violência doméstica entende-se que as mulheres sofreram todos os tipos de violência, inclusive a de gênero.

Todas as análises foram realizadas utilizando-se o programa IBM/SPSS v.20. Como todas as variáveis foram categorizadas, os resultados estão apresentados em frequências simples e acumuladas e as comparações entre os grupos foram feitas por meio de testes do quiquadrado, assumindo nível de significância de 5\%.

\section{Resultados e Discussão}

Das 440 mulheres que denunciaram a violência, 373 a formalizaram na rotina e 67 no plantão no período do estudo (Tabela 1 ).

\section{Faixa etária}

Não foi constatada diferença estatisticamente significativa das faixas etárias em relação ao local de realização do BO, porém, observou-se predominância de denúncias realizadas por mulheres na faixa etária entre 20 a 39 anos, tanto na rotina quanto no plantão.

$\mathrm{Na}$ literatura a faixa etária das mulheres em situação de violência difere em relação ao ano, região da pesquisa e número de participantes. Em estudo realizado na cidade de Salvador (BA), no ano de 2003, em um serviço de urgência e emergência com 701 mulheres, a idade predominante foi de $40 \operatorname{anos}^{13}$. Já, em estudos mais recentes realizados em Delegacias de Defesa da Mulher em Minas Gerais ${ }^{14}$ e Rio Grande do Sul ${ }^{15}$ predominaram as faixas etárias de 20 a 39 anos coincidindo assim com dados do presente estudo. Ressalta-se que o estudo na Bahia foi realizado antes da promulgação da Lei Maria da Penha, em um local em que é ainda mais predominante a cultura do patriarcado e num serviço de urgência e emergência, ou seja, as mulheres não procuraram o serviço por iniciativa própria. Por outro lado, os estudos em que a faixa etária era menor foram realizados seis anos após a promulgação da Lei Maria da Penha (2006), em DDM e em Estados em que a discussão e as políticas de enfrentamento da violência contra a mulher estão mais avançadas ${ }^{6}$.

\section{Escolarização}

Em relação à escolaridade, esta variou entre ensino fundamental completo e ensino médio 
Tabela 1. Distribuição e diferenças das características sociodemográficas das mulheres que formalizaram denúncia na rotina e no plantão.

\begin{tabular}{|c|c|c|c|c|c|}
\hline & \multicolumn{2}{|c|}{ Rotina } & \multicolumn{2}{|c|}{ Plantão } & \multirow{2}{*}{ p-valor } \\
\hline & $\mathbf{N}$ & $\%$ & $\mathbf{N}$ & $\%$ & \\
\hline \multicolumn{6}{|l|}{ Escolaridade } \\
\hline Superior completo & 26 & 8,1 & 3 & 5,3 & $0,783^{\star}$ \\
\hline Médio completo & 131 & 41 & 25 & 43,8 & \\
\hline Fundamental completo & 158 & 49,5 & 28 & 49 & \\
\hline Fundamental incompleto & 2 & 0,7 & 1 & 1,9 & \\
\hline Não alfabetizado & 2 & 0,7 & 0 & 0 & \\
\hline \multicolumn{6}{|l|}{ Possui filhos } \\
\hline Não & 229 & 61,4 & 34 & 50,7 & $0,101^{\star}$ \\
\hline Sim & 144 & 38,6 & 33 & 49,3 & \\
\hline \multicolumn{6}{|l|}{ Cor } \\
\hline Branca & 293 & 80,9 & 52 & 83,9 & $<0,001^{\star}$ \\
\hline Parda & 62 & $17,2_{\mathrm{a}}$ & 3 & $4,8_{\mathrm{b}}$ & \\
\hline Negra & 7 & $1,9_{\mathrm{a}}$ & 7 & $11,3_{\mathrm{b}}$ & \\
\hline \multicolumn{6}{|l|}{ Estado civil } \\
\hline Casada & 88 & 25 & 11 & 18,60 & $0,035^{\star}$ \\
\hline Divorciada & 48 & 13,60 & 5 & 8,50 & \\
\hline Solteira & 216 & 61,40 & 42 & 71,20 & \\
\hline \multirow[t]{2}{*}{ Viúva } & 0 & $0_{a}$ & 1 & $1,7_{b}$ & \\
\hline & (média) & $\begin{array}{l}\text { (desvio } \\
\text { padrão) }\end{array}$ & (média) & $\begin{array}{l}\text { (desvio } \\
\text { padrão) }\end{array}$ & \\
\hline Idade & 32,5 & 8,7 & 31,4 & 7,8 & $0,344 \dagger$ \\
\hline Tempo de convivência com o agressor & 7,5 & 6,4 & 6,1 & 5,8 & $0,174 \dagger$ \\
\hline
\end{tabular}

* Teste de Quiquadrado. $†$ Teste t-student.

a, b: porcentagens seguidas da mesma letra minúscula não diferem significativamente ao nível de $5 \%$ pelo teste $\mathrm{Z}$ com correção de Bonferroni.

completo, com poucas mulheres sem alfabetização. Essa distribuição pode ser o reflexo do município, onde em 2010, 65,56\% da população de 18 a 24 anos apresentava pelo menos o Ensino Médio Completo e uma taxa de analfabetismo de $4,11 \%$ na população de 15 anos e mais ${ }^{16}$. Chamou atenção o elevado número de BO sem informação de escolaridade, apesar de a denúncia ter sido realizada pela própria mulher.

\section{Cor da pele}

As mulheres brancas não apresentaram diferenças significantes quanto ao período da denúncia, já as pardas e negras o fizeram mais na rotina e nos plantões, respectivamente. As diferenças e o impacto da violência sofrida por mulheres negras estão na combinação das múltiplas desigualdades e formas de discriminação que afetam essas mulheres tais como: gênero, raça, etnia, classe e orientação e identidade sexual ${ }^{17,18}$. A taxa de homicídios por agressão é de 3,2/100 mil entre brancas e de 7,2 entre negras ${ }^{14,18}$. Inclusive, se- gundo o Mapa da Violência de 2015, no período entre 2003 e 2013 ocorreu uma queda de 9,8\% no total de homicídios de mulheres brancas, mas os homicídios das mulheres negras aumentaram em $54,2 \%{ }^{19,20}$.

$\mathrm{O}$ fato de mais mulheres negras realizarem a ocorrência no plantão demonstra ainda mais a vulnerabilidade desse grupo na busca pela garantia de seus direitos, que também pode estar associada a determinantes como tipo e horário de trabalho, baixa escolarização, entre outros ${ }^{20,21}$ (Tabela 2).

\section{Meses do ano}

Procurou-se verificar se havia diferença na distribuição das denúncias durante o ano em que o levantamento foi realizado, de abril de 2013 a março de 2014.

Não foi constatada diferença estatisticamente significativa na maioria dos meses de $2013 \mathrm{em}$ relação ao horário de realização das denúncias, com exceção de julho e dezembro, quando há um 
Tabela 2. Distribuição e diferenças das características das denúncias na rotina e no plantão.

\begin{tabular}{|c|c|c|c|c|c|}
\hline & \multicolumn{2}{|c|}{ Rotina } & \multicolumn{2}{|c|}{ Plantão } & \multirow{2}{*}{ p-valor ${ }^{\star}$} \\
\hline & $\mathbf{n}$ & $\%$ & $\mathbf{N}$ & $\%$ & \\
\hline \multicolumn{6}{|l|}{ Mês de ocorrência } \\
\hline Abril 2013 & 39 & $10,5_{a}$ & 7 & $10,4 \mathrm{a}$ & \\
\hline Maio & 30 & 8 & 9 & $13,4 \mathrm{a}$ & \\
\hline Junho & 31 & $8,3_{\mathrm{a}}$ & 9 & 13,4 & \\
\hline Julho & 11 & $2,9 a_{a}$ & 8 & $11,9_{\mathrm{b}}$ & $<0,001$ \\
\hline Agosto & 41 & $11_{\mathrm{a}}$ & 6 & $9_{a}$ & \\
\hline Setembro & 32 & $8,7_{\mathrm{a}}$ & 7 & 10,4 & \\
\hline Outubro & 30 & 8 a & 6 & $9_{\mathrm{a}}$ & \\
\hline Novembro & 31 & $8,3_{\mathrm{a}}$ & 3 & $4,6_{\mathrm{a}}$ & \\
\hline Dezembro & 28 & $7,5_{\mathrm{a}}$ & 12 & $17,9_{\mathrm{b}}$ & \\
\hline Janeiro 2014 & 35 & $9,4_{\mathrm{a}}$ & 0 & $0_{\mathrm{b}}$ & \\
\hline Fevereiro & 28 & $7,5_{\mathrm{a}}$ & 0 & $0_{\mathrm{b}}$ & \\
\hline Março & 37 & $9,9{ }_{\mathrm{a}}$ & 0 & $0_{\mathrm{b}}$ & \\
\hline \multicolumn{6}{|l|}{ Realizado no final de semana } \\
\hline Não & 211 & $56,6_{a}$ & 19 & $28,4_{b}$ & $<0,001$ \\
\hline Sim & 162 & $43,4{ }_{a}$ & 48 & $71,6_{b}$ & \\
\hline \multicolumn{6}{|l|}{ Flagrante } \\
\hline Não & 365 & $98,9_{a}$ & 55 & $84,6_{\mathrm{b}}$ & $<0,001$ \\
\hline Sim & 4 & $1,1_{\mathrm{a}}$ & 10 & $15,4_{b}$ & \\
\hline \multicolumn{6}{|c|}{ Solicitação de medidas protetivas de emergência } \\
\hline Não & 157 & $47,3_{\mathrm{a}}$ & 22 & $37,9_{\mathrm{a}}$ & 0,003 \\
\hline Sim & 55 & $16,6_{\mathrm{a}}$ & 17 & $29,3_{\mathrm{b}}$ & \\
\hline Agressor preso em flagrante & 2 & $0,6_{\mathrm{a}}$ & 3 & $5,2_{b}$ & \\
\hline Não desejou & 118 & $35,5_{\mathrm{a}}$ & 16 & $27,6_{a}$ & \\
\hline \multicolumn{6}{|l|}{ Local de ocorrência } \\
\hline Casa & 306 & 82,90 & 57 & 85,10 & 0,636 \\
\hline Ambiente público & 49 & 13,30 & 9 & 13,40 & \\
\hline Trabalho & 14 & 3,80 & 1 & 1,50 & \\
\hline \multicolumn{6}{|l|}{ Conduzida à delegacia } \\
\hline Sozinha & 236 & $88,1_{\mathrm{a}}$ & 24 & $46,1_{b}$ & $<0,001$ \\
\hline Familiares & 19 & $7,1_{\mathrm{a}}$ & 6 & $11,5_{\mathrm{a}}$ & \\
\hline Guarda Municipal & 11 & $4,1_{\mathrm{a}}$ & 11 & $21,2_{\mathrm{b}}$ & \\
\hline Outros serviços do Município & 2 & $0,7_{\mathrm{a}}$ & 11 & $21,2_{b}$ & \\
\hline \multicolumn{6}{|l|}{ Encaminhada ao IML } \\
\hline Não & 273 & $76_{a}$ & 32 & $50_{\mathrm{b}}$ & $<0,001$ \\
\hline Sim & 86 & $24 \mathrm{a}$ & 32 & 50 & \\
\hline \multicolumn{6}{|l|}{ Hematomas aparente } \\
\hline Não & 300 & $80,4_{a}$ & 45 & $67,2_{\mathrm{b}}$ & 0,015 \\
\hline Sim & 73 & $19,6_{\mathrm{a}}$ & 22 & $32,8_{b}$ & \\
\hline \multicolumn{6}{|l|}{ Necessidade de hospitalização } \\
\hline Não & 371 & $99,5_{a}$ & 61 & $91_{b}$ & $<0,001$ \\
\hline Sim & 2 & $0,5_{\mathrm{a}}$ & 6 & $9_{\mathrm{b}}$ & \\
\hline \multicolumn{6}{|l|}{ Violência doméstica } \\
\hline Não & 307 & $82,3_{\mathrm{a}}$ & 34 & $50,7_{\mathrm{b}}$ & $<0,001$ \\
\hline Sim & 66 & $17,7_{\mathrm{a}}$ & 33 & $49,3_{\mathrm{b}}$ & \\
\hline \multicolumn{6}{|l|}{ Violência psicológica } \\
\hline Não & 372 & 99,70 & 67 & 100 & 0,671 \\
\hline Sim & 1 & 0,30 & 0 & 0 & \\
\hline
\end{tabular}


Tabela 2. Distribuição e diferenças das características das denúncias na rotina e no plantão.

\begin{tabular}{|c|c|c|c|c|c|}
\hline & \multicolumn{2}{|c|}{ Rotina } & \multicolumn{2}{|c|}{ Plantão } & \multirow{2}{*}{ p-valor ${ }^{\star}$} \\
\hline & $\mathbf{n}$ & $\%$ & $\mathbf{N}$ & $\%$ & \\
\hline \multicolumn{6}{|l|}{ Ameaça } \\
\hline Não & 143 & $38,3_{\mathrm{a}}$ & 36 & $53,7_{\mathrm{b}}$ & 0,018 \\
\hline Sim & 230 & $61,7_{\mathrm{a}}$ & 31 & $46,3_{\mathrm{b}}$ & \\
\hline \multicolumn{6}{|c|}{ Danos patrimoniais } \\
\hline Não & 364 & 97,60 & 65 & 97 & 0,782 \\
\hline Sim & 9 & 2,40 & 2 & 3 & \\
\hline \multicolumn{6}{|c|}{ Violência sexual } \\
\hline Não & 372 & 99,70 & 67 & 100 & 0,671 \\
\hline Sim & 1 & 0,30 & 0 & 0 & \\
\hline \multicolumn{6}{|c|}{ Lesão corporal } \\
\hline Não & 270 & $72,4 a$ & 28 & $41,8_{\mathrm{b}}$ & $<0,001$ \\
\hline Sim & 103 & $27,6_{a}$ & 39 & $58,2_{\mathrm{b}}$ & \\
\hline \multicolumn{6}{|l|}{ Injúria } \\
\hline Não & 326 & 87,40 & 60 & 89,60 & 0,621 \\
\hline Sim & 47 & 12,60 & 7 & 10,40 & \\
\hline
\end{tabular}

* Teste de Quiquadrado.

a, b: porcentagens seguidas da mesma letra minúscula não diferem significativamente ao nível de $5 \%$ pelo teste $\mathrm{Z}$ com correção de Bonferroni.

predomínio, em termos relativos, dos casos formalizados no plantão. Chama atenção o fato de que nos três primeiros meses de 2014 não há registro de boletim de ocorrência no plantão, o que dificulta a análise comparativa desses três meses.

É importante lembrar, que os boletins de ocorrência formalizados na delegacia civil no período do plantão, posteriormente são encaminhados para a DDM, e o campo deste estudo se deu na DDM. Deste modo, uma possível hipótese para a ocorrência desse fato seria uma mudança de conduta na delegacia civil, ou mesmo dos escrivães responsáveis pelo registro do BO desta delegacia.

\section{Prisão em flagrante}

Nas ocorrências formalizadas no plantão houve mais prisões em flagrante, mais solicitações de medida protetiva de urgência e maior número de condução da mulher à DDM pela guarda municipal ou outros serviços.

Essas diferenças suscitaram três situações para se repensar o perfil das ocorrências e a garantia de direito das mulheres em situação de violência: o flagrante como possibilidade de punição do agressor; o requerimento da medida protetiva como garantia de proteção da mulher; e a condução da mulher à delegacia para formalização da ocorrência como divisor de águas para o protagonismo.
O flagrante ocorre nas situações em que o agressor está praticando a ação ou logo após praticá-la. Embora não haja prazo estipulado, o flagrante será considerado enquanto perdurar a perseguição do agressor, cessando somente com sua interrupção ${ }^{22}$.

$\mathrm{O}$ requerimento das medidas protetivas de urgências estabelecidas com a Lei 11.340/2006 ${ }^{6}$ possibilitam a proteção imediata da mulher ao reprimir a situação de violência e controlar o comportamento do agressor. O objetivo da medida é tirar a mulher da situação de risco no período entre as investigações policiais e o início da ação penal. De ordem judicial, essas medidas visam ainda garantir a proteção da mulher ao determinar o afastamento do agressor do lar (caso eles morem juntos), ao proibi-lo de se aproximar da mulher e dos filhos, de frequentar os mesmos lugares que eles e de manter contato, entre outras que o juiz julgue necessário.

Essas medidas também podem ser aplicadas cumulativamente e o descumprimento pode acarretar na prisão preventiva ${ }^{6}$. Para as mulheres a vantagem de solicitar a medida pauta-se na garantia de acolhimento na rede de proteção e de apoio, tais como: proteção policial para retirada dos pertences da casa do agressor, auxílio policial para retornar ao lar, restituição dos bens que estiverem em posse do agressor, determinação da separação de corpos, encaminhamento para casas abrigos e/ou para programas de proteção e 
acolhimento, entre outros. É importante ressaltar que para solicitar a medida é pré-requisito o registro de um $\mathrm{BO}$ para que o delegado remeta esse pedido ao juiz, o qual deverá ser apreciado em até 48 horas $^{6}$.

A necessidade de condução e a gravidade das agressões denunciadas no plantão trazem à tona questionamentos sobre a autonomia e o empoderamento dessas mulheres na busca e na garantia de seus direitos. O fato é que ainda predomina na sociedade contemporânea a racionalidade sexista que destinou às mulheres um local de subordinação ao masculino. Por muito tempo predominou a ideologia patriarcal, particularmente no sistema político e religioso, impedindo as mulheres de manifestar e vivenciar autonomia e liberdade nos seus relacionamentos. Os avanços conquistados em termos de legislações e políticas ainda estão presos no ideal de igualdade de gênero, mas, a realidade ainda contempla diferentes contextos e formas de apreender e definir os papéis sociais. O fato é que a organização familiar vigente ainda está alicerçada no modelo patriarcal burguês, que reforça a desvalorização da mulher restringindo suas funções à tarefas domésticas, aos filhos e ao marido, impedindo-as de enxergar novos horizontes e novos projetos de vida. Deste modo, a situação de violência acaba sendo para as mulheres, mais uma norma pré-determinada e sem possibilidades de alteração ${ }^{23}$.

As DDM surgiram com a função de proteger, amparar as mulheres e frear a crueldade masculina, priorizando a recepção e o acolhimento de mulheres em situação de violência em um local propício direcionado para a peculiaridade do seu caso e, principalmente, visando enfrentar situações degradantes ocorridas e atribuídas ao espaço privado ${ }^{24}$. Contudo, trinta e dois anos após a implantação da primeira DDM, o serviço não está disponível à noite, nos feriados e nos finais de semana, o que dificulta o acesso a um serviço especializado e capacitado para atender essa demanda e enfraquece o ideal de proteção e acolhimento trazido com a criação das DDM. Portanto, é um retrocesso ter que formalizar denúncia de violência doméstica no plantão policial, pois, a DDM foi uma alternativa a esse modelo de serviço, que muitas vezes impedia, diminuía e desqualificava as situações de violência vivenciadas pelas mulheres, reforçando posicionamentos machistas e opressores ${ }^{6,7,25}$.

\section{A gravidade das ocorrências formalizadas no plantão}

Os resultados revelaram ainda, que as mulheres que procuraram o plantão foram as que mais apresentaram hematomas aparentes, necessidade de hospitalização e encaminhamento ao IML, denunciando assim a intensidade da agressão e a gravidade das denúncias. Estudos que têm por base serviços de urgência e emergência em saúde, ressaltam que apesar de muitas mulheres chegarem ao serviço no período diurno, as agressões ocorrem predominantemente à noite ${ }^{25}$. A busca da mulher por atendimento em mais de um serviço, indica a necessidade de adequação dos serviços de atendimento às vítimas quanto as suas competências e aos períodos de funcionamento ${ }^{25}$.

De acordo com a Política Nacional de Enfrentamento à Violência contra as Mulheres de 2007², geralmente a violência contra a mulher segue um ciclo formado por três fases. Na primeira, denominada de construção de tensão no relacionamento, ocorrem pequenas violências como as verbais, ameaças e destruição de objetos que muitas vezes estão relacionados a crise de ciúmes. Nesses episódios as mulheres se sentem culpadas pela alteração de comportamento do agressor e tentam acalmá-lo sendo dóceis e prestativas. Elas acreditam que podem impedir futuras agressões e que essas não ocorrerão mais. Na segunda fase, denominada de explosão da violência, ocorre o descontrole e a destruição, é nesta fase que ocorrem as agressões mais severas como as físicas e os traumas. Esse é o ápice das agressões. Essa fase é mais curta que a primeira e abre precedentes para a terceira fase. Denominada de reconciliação e/ou lua de mel, a terceira fase é marcada pelo arrependimento do agressor, momento em que há demonstração do remorso e muito medo da separação. Normalmente nesse momento ele jura que não haverá mais agressões e presenteia a mulher tentando demonstrar a veracidade do arrependimento e da culpa ${ }^{7}$.

\section{Os tipos de violência}

No presente estudo os tipos de violência mais denunciados no plantão foram a violência doméstica e a lesão corporal, enquanto a ameaça foi mais denunciada na rotina. Evidenciando que o tipo de violência "ameaça" se relaciona à primeira fase do ciclo da violência, a de tensão no relacionamento. Enquanto no plantão a "lesão corporal" está relacionada à segunda fase, de explosão ${ }^{7}$. 
Chama atenção um caso de violência sexual por parceiro íntimo formalizado na rotina, pois a mulher ao formalizar a queixa no espaço policial, demonstrou claramente que ela não somente reconheceu a violência sofrida como também a denunciou. Entretanto, costumeiramente há dificuldade de se reconhecer esse tipo de violência nas relações de parcerias estáveis, tanto por parte das mulheres, quanto por parte dos serviços de proteção às mulheres, devido a carga cultural que permeia esses contextos e da crença de que a mulher deve satisfazer o homem em todas as esferas, inclusive sexualmente, portanto, em geral as agressões são entendidas como dever de esposa e não são denunciadas ${ }^{26}$.

Nesse sentido, pode ter havido mais casos de violência sexual no grupo estudado que não foram denunciados, demonstrando a importância de uma rede de serviços organizada para acolher as mulheres sob a perspectiva crítica das relações de gênero, possibilitando a elas uma tomada de consciência da atual ordem social que orienta os gêneros.

O imediatismo e a gravidade das queixas de violência, formalizadas no plantão policial, revela a importância de se trabalhar esse tema preventivamente nos serviços de saúde, de assistência social e nas DDM, conforme estabelecido pela Lei Maria da Penha. A referida lei, preconiza, inclusive, a promoção de ações ampliadas, integradas e intersetoriais de prevenção dos vínculos familiares e comunitários com foco na independência e no protagonismo dos indivíduos, nesse caso, das mulheres em seus territórios de abrangência ${ }^{6,7,27,28}$.

Porém, apesar dessas políticas terem incorporado em seus objetivos e diretrizes formas de se abordar e prevenir situações de violência contra a mulher, a efetivação dessas na prática ainda é incipiente. $\mathrm{O}$ fato é que a violência contra a mulher ainda é invisível nos serviços de atenção primária à saúde e nos serviços de proteção social básica $^{7,28-30}$.

A invisibilidade nos serviços de saúde se dá por meio da manutenção do modelo médico centrado, pautado em queixas biológicas e traumas físicos. Isso ocorre devido a duas situações importantes: a primeira se relaciona a dificuldade de detecção da violência e está intrinsicamente ligada a falta de formação dos profissionais para atuar em situações não físicas e biológicas. Sendo assim, eles não compreendem que um fenômeno sociocultural como a violência pode interferir no processo saúde-doença e acabam focando simplesmente no que é visto e narrado pela mulher; na segunda situação os profissionais conseguem detectar a violência, mas não sabem como conduzir os casos e nem reconhecem os equipamentos sociais que fazem parte da rede de proteção ${ }^{31-35}$. Muitas vezes a própria mulher não consegue perceber que está vivendo uma situação de violência, justamente nessas situações que ela precisa do apoio profissional para enxergar a violência. Em geral, todo esse processo ocorre na primeira fase do ciclo da violência ${ }^{7}$.

Há, ainda, situações em que os profissionais de saúde apostam na escuta e focam em ouvir a queixa quando a mulher decide falar, e ao invés de fornecer a atenção que é de sua competência a encaminha a outros serviços, sem a coresponsabilização pelo caso. Ao ter que percorrer diferentes serviços e contar e recontar sua história, as mulheres acabam revivendo e ressentindo a situação de violência ${ }^{36,37}$. Portanto, os serviços de atenção primária à saúde, além de não exercer o papel de coordenador da rede atenção à saúde, também não se constituem porta de entrada para os casos de violência contra a mulher ${ }^{38}$.

Ressalta-se, inclusive, a necessidade de articulação entre os serviços de urgência e emergência e da atenção primária, pois, se os primeiros são mais acionados nos casos de violência física e sexual, os segundos, são por conta de sintomas inespecíficos, resultante de longos períodos de violência sofrida.

A articulação destes serviços de saúde e dos demais que atuam nos casos de violência contra a mulher, como os Centros de Referências Especializados de Assistência Social (CREAS) e as DDM, possibilitariam uma ação efetiva do ponto de vista da integralidade da mulher.

Os profissionais que operam as duas políticas, de saúde e de assistência social, dada a própria organização dos mesmos, não conseguem apreender e incorporar a regularidade e continuidade nos atendimentos dos casos de violência contra a mulher. Em geral, realizam ações pontuais e normativas para os casos cuja complexidade exige ressignificação de hábitos e cultura e que, portanto, requerem transformações contínuas na busca por uma nova ordem social, a de igualdade de gênero. Deste modo, os profissionais atuantes nas UBS/ESF e nos CRAS precisam romper com a pontualidade no atendimento médico centrado na atenção primária a saúde, e assistencialista na proteção social básica ${ }^{39,40}$.

$\mathrm{O}$ fato de se notificar a violência sem ações articuladas e integradas não diminui a vulnerabilidade das mulheres. Estudo realizado com dados do SINAN e SIM para o Brasil no período de 2011 
a 2015 indica que o risco de as mulheres notificadas por violência morrer por agressão é maior do que o da população feminina em geral $^{40}$.

A visão holística sobre o fenômeno da violência contra a mulher deveria abranger também os profissionais que trabalham nas DDM, para garantir a mulher o acolhimento livre de rótulo e de preconceito no momento da formalização do boletim de ocorrência. Foi exatamente essa lógica que orientou a promulgação da Lei Maria da Penha e da Política de Enfrentamento da Violência contra a Mulher, sendo assim, não faz sentido fragmentar o atendimento das mulheres que precisam formalizar a denúncia de acordo com o horário de expediente ${ }^{6,7}$.

\section{A importância de uma rede integrada de proteção}

A Política Nacional de Enfrentamento da violência contra a mulher propõe um trabalho articulado em rede, para superar a desarticulação dos diferentes níveis de atenção no combate à violência contra a mulher. $O$ conceito de rede de atendimento que norteia as ações de política de enfrentamento reporta-se à atuação articulada das diferentes instituições e serviços governamentais e não governamentais e a comunidade, objetivando ampliar e melhorar a qualidade do atendimento para identificação e encaminhamento adequado das mulheres em situação de violência, bem como desenvolver estratégias efetivas de prevenção ${ }^{6,7,31}$. No campo da saúde a importância da efetivação de um trabalho em rede vem sendo debatido desde a década de 90, devido à preocupação em garantir a integralidade, a equidade e a universalidade na atenção à saúde da população ${ }^{41}$.

Especificamente nos casos de violência contra a mulher é de suma importância a integração dos serviços para ampliar a proteção, garantir a prevenção e prestar atendimento eficaz e contínuo para os casos, por ser a violência um fenômeno sociocultural caracterizado como crime e que interfere no processo saúde, a resposta aos casos deve ser de cunho intersetorial, visando superar a forma isolada, fragmentada e pontual dos atendimentos prestados nos diferentes serviços ${ }^{31}$.

$\mathrm{O}$ fato das DDM permanecerem fechadas em um período de extrema vulnerabilidade para as mulheres pode restringir e limitar a garantia de seus direitos, além de impossibilitar o trabalho em rede. Além disso, ser atendida em uma Delegacia que não foi preparada para esse tipo de demanda, também dificulta as orientações e in- corporação da mulher na rede de atendimento, e vai contra a lógica de atendimento intersetorial proposta pela Política de Enfrentamento da Violência contra a Mulher e pela Lei Maria da Penha, conforme explicitado anteriormente $e^{6,7}$.

A importância de se prestar assistência integral e qualificada às mulheres, por meio de uma rede de atendimento, tem como foco a trajetória da mulher pelos serviços, denominada rota crítica ${ }^{41,42}$. Esse percurso deve possuir várias portas de entrada para a rede de atendimento, como os serviços de urgência e emergência da saúde, os serviços de assistência social e as DDM, além de outros recursos comunitários, cujo trabalho deve ser realizado de forma articulada e integrada visando prestar uma assistência que não revitimize a mulher ${ }^{42}$.

Deve-se investir em estratégias de formação e educação continuada de modo que todos esses serviços tornem-se aptos a reconhecer a ordem societária patriarcal que orienta a cultura brasileira e a identificar os ciclos da violência contra a mulher. Reconhecer o momento e circunstâncias do ciclo da violência que a mulher está vivenciando possibilita aos profissionais acolher e identificar a necessidade de acionar os serviços de proteção que ela precisa naquele momento, sem realizar pré-julgamentos e construindo em conjunto as melhores alternativas.

Conforme indicado anteriormente, as mulheres que formalizaram ocorrência no plantão se encontravam na fase da explosão da violência, denominada segunda fase do ciclo da violência ${ }^{7}$, estágio em que estão presentes todos os tipos de violência com maior intensidade, gravidade e aumento das agressões, com risco iminente de morte. Se nesta fase a mulher não for encaminhada à rede de atendimento, que envolve serviços referente às políticas de saúde, assistência social, segurança pública e assistência judiciária, ela corre o risco de continuar no relacionamento abusivo e vivenciar a fase posterior denominada "lua de mel" fazendo com que a mulher lhe dê outra chance ${ }^{7}$.

Deste modo, dado o caráter paliativo e pontual dos serviços prestados nos plantões policiais, dificilmente as mulheres que lavram BO nas Delegacias Civis serão acolhidas, orientadas ou mesmo incorporadas à rede de proteção do município $^{31}$.

A apreensão do fenômeno da violência contra a mulher, sobre a perspectiva socio-histórica das desigualdades de gênero, pelos profissionais que compõem a rede de atendimento nas delegacias especializadas, nos serviços de saúde, de as- 
sistência social e no judiciário poderá contribuir para desconstrução da mentalidade vigente ${ }^{31}$. Mas, para que isso de fato ocorra, os profissionais desses serviços terão que se apropriar desses conteúdos, apreender a problemática como sendo de responsabilidade do serviço e ressignificarem também sua visão de mundo e inserção nessa ordem social, uma vez que o modo de compreender a violência influencia na forma de detectá-la e de enfrentá-la.

\section{Conclusão}

Para além da importante decisão da mulher em realizar uma denúncia de violência pelo parceiro, fazê-la no período de rotina em delegacia especializada ou no período de plantão em delegacias civis decorre das características do evento vivenciado.

As denúncias registradas no plantão diferenciaram-se pelo flagrante do agressor, aumento das solicitações de medidas protetivas de urgência e maior número de mulheres que foram conduzidas à delegacia pela polícia e pela guarda municipal. A gravidade das agressões se manifestou em um número maior de hematomas aparentes, necessidade de hospitalização e encaminhamento ao IML.

Neste estudo os casos que chegaram às delegacias civis extrapolaram em gravidade os atendidos na DDM, no período diurno, demonstrando assim, que esta necessita ampliar o horário de funcionamento oferecendo à mulheres o acolhimento necessário conforme o que é preconizado, além de possibilitar o desencadeamento de ações integradas dos diferentes serviços que compõe a rede de assistência.

Dada a relevância do tema, aponta-se a necessidade de realização de estudos em delegacias de municípios de maior porte com vistas a verificar a existência de diferenças conforme apresentado no presente estudo, e subsidiar mudanças no funcionamento das Delegacias de Defesa da Mulher de modo a valorizá-las como porta de entrada de uma atenção em rede que avance na consolidação dos direitos da mulher.

\section{Colaboradores}

DF Machado: concepção do artigo, revisão bibliográfica, redação final do texto. MAS Almeida e ERL Castanheira: revisão crítica do texto. JM Bernardes e A Dias: análise dos dados. 


\section{Referências}

1. Schraiber LB, d'Oliveira AFPL, Portella AP, Menicucci E. Violência de gênero no campo da saúde coletiva: conquistas e desafios. Cien Saude Colet 2009; 14(4):1019-1027.

2. Pasinato $\mathrm{W}$. Acesso à justiça e violência doméstica $\mathrm{e}$ familiar contra as mulheres: as percepções dos operadores jurídicos e os limites para a aplicação da Lei Maria da Penha. Rev Direito GV 2015; 11(2):407-428.

3. Santos CM. Da delegacia da mulher à lei Maria da Penha: lutas feministas e políticas públicas sobre violência contra mulheres no Brasil. Coimbra: Centro de Estudos Sociais, Universidade de Coimbra; 2008.

4. Nobre MT, Barreira C. Controle social e mediação de conflitos: as delegacias da mulher e a violência doméstica. Sociologias (Porto Alegre) 2008; 10(20):138-163.

5. Souza L, Cortez MB. A delegacia da mulher perante as normas e leis para o enfrentamento da violência contra a mulher: um estudo de caso. Rev Adm Publica 2014; 48(3):621-639.

6. Brasil. Lei $\mathrm{n}^{\circ} 11.340$, de 07 de agosto de 2006. Cria mecanismos para coibir a violência doméstica e familiar contra a mulher, altera o Código de Processo Penal, o Código Penal e a Lei de Execução Penal; e dá outras providências. Diário Oficial da União 2006; 8 ago.

7. Brasil. Presidência da República. Política Nacional de Enfrentamento à Violência contra as Mulheres. Brasília: Secretaria de Políticas para as Mulheres; 2007.

8. Pasinato W, Santos CM. Mapeamento das Delegacias da Mulher no Brasil [documento na Internet]. Campinas: Núcleo de Estudos de Gênero Pagu, Universidade Estadual de Campinas; 2008. [acessado 2018 Fev 20]. Disponível em: http://www.ces.uc.pt/nucleos/needa/ documentos/MAPEOBrasil.pdf

9. Saffioti HIB. Já se mete a colher em briga de marido e mulher. São Paulo Perspec 1999; 13(4):82-91.

10. Izumino WP. Violência contra a mulher no Brasil: acesso à Justiça e a construção da cidadania de Gênero. In: Painel do VII Congresso Luso-Afro-Brasileiro de Ciências Sociais [artigo na Internet]; 2004; Coimbra. [acessado 2018 Fev 21]. Disponível em: http://www. ces.uc.pt/lab2004/inscricao/pdfs/painel112/WaniaPasinatoIzumino.pdf

11. Echeverria JGM, Oliveira MHB, Erthal RMC. Violência doméstica e trabalho: percepções de mulheres assistidas em um Centro de Atendimento à Mulher. Saude Debate 2017; 41(n. esp. 2):13-24.

12. Instituto Brasileiro de Geografia e Estatística (IBGE). Censo demográfico 2010 [página na Internet]. Brasília: IBGE; 2010. [acessado 2017 Mar 13]. Disponível em: www.ibge.gov.br

13. Silva IV. Violência contra mulheres: a experiência de usuárias de um serviço de urgência e emergência de Salvador, Bahia, Brasil. Cad Saude Publica 2003; 19(Supl 2):263-272.

14. Souza AKA, Nogueira DA, Gradim CVC. Perfil da violência doméstica e familiar contra a mulher em um município de Minas Gerais, Brasil. Cad Saude Colet 2013; 21(4):425-431.

15. Acosta DF, Gomes VLO, Barlem ELD. Perfil das ocorrências policiais de violência contra a mulher. Acta Paul Enferm 2013; 26(6):547-553.
16. Fundação Seade. Perfil dos Municípios Paulistas. Educação [página na Internet]. São Paulo: Fundação Seade; 2018. [acessado 2018 Fev 21]. Disponível em: http://www.perfil.seade.gov.br/?

17. Oliveira ER. Violência doméstica e familiar contra a mulher: um cenário de subjugação do gênero feminino. Rev LEVS/UNESP-Marília 2012; 9:150-165.

18. Brasil. Ministério da Justiça (MJ). Diagnóstico dos homicídios no Brasil: subsídios para o Pacto Nacional pela Redução de Homicídios. Brasília: MJ; 2015.

19. Waiselfisz JJ. Mapa da violência 2015: homicídio de mulheres no Brasil. Brasília: ONU Mulheres; 2015.

20. Marcondes MM, organizador. Dossiê mulheres negras: retrato das condições de vida das mulheres negras no Brasil. Brasília: Ipea; 2013.

21. Waiselfisz JJ. Mapa da violência 2012: a cor dos homicídios no Brasil. Rio de Janeiro: CEBELA, FLACSO; 2012.

22. Brasil. Decreto-Lei no 3.689, de 3 de outubro de 1941. Código de Processo Penal. In: Angher AJ. Vade mecum universitário de direito RIDEEL. $8^{\mathrm{a}}$ ed. São Paulo: RIDEEL; 2010. p. 351-395.

23. Brasil. Governo Federal. Secretaria de Assuntos Estratégicos da Presidência da República. Instituto de Pesquisa Econômica Aplicada (Ipea). Pesquisa sobre tolerância social à violência contra as mulheres. Brasília: Ipea; 2014. [acessado 2017 Mar 8]. Disponível em: http://www.compromissoeatitude.org br/wpcontent/uploads/2014/04/IPEA_sips_violenciamulheres04042014.pdf

24. Garcia LP, Duarte EC, Freitas LRSD, Silva GDMD. Violência doméstica e familiar contra a mulher: estudo de casos e controles com vítimas atendidas em serviços de urgência e emergência. Cad Saude Publica [periódico na Internet]. 2016 [acessado 2017 Out 2]; 32(4):e00011415. Disponível em: http://www.scielo.br/scielo.php?script=sci_arttext\&pid $=$ S0102-311X2016000400704\&lng $=\mathrm{pt}$

25. Cortizo MC, Goyeneche PL. Judiciarização do privado e violência contra a mulher. Rev Katál 2010; 13(1):102-109.

26. Schraiber LB, D’Oliveira AFPL, França Junior I. Violência sexual por parceiro íntimo entre homens e mulheres no Brasil urbano, 2005. Rev Saude Publica 2008; 42(Supl. 1):127-137.

27. Sousa ARD, Pereira Á, Paixão GPDN, Pereira NG, Campos LM, Couto TM. Repercussões da prisão por violência conjugal: o discurso de homens. Rev Lat Am Enfermagem [periódico na Internet]. 2016 [acessado 2017 Out 1]; 24:e2847. Disponível em: http://www.scielo.br/scielo.php?script=sci_arttext\&pid=S0104-11692016000100440\&lng=pt

28. Brasil. Ministério da Saúde (MS). Secretaria de Atenção À Saúde. Departamento de Atenção Básica. Política Nacional de Atenção Básica. 4a ed. Brasília: MS; 2007. (Série E. Legislação de Saúde; Série Pactos pela Saúde 2006; v. 4).

29. Brasil. Ministério do Desenvolvimento Social e Combate à Fome (MDS). Política Nacional de Assistência Social - PNAS. Brasília: MDS; 2004.

30. Brasil. Ministério do Desenvolvimento Social e Combate à Fome (MDS). Tipificação Nacional de Serviços Socioassistenciais. Brasília: MDS; 2009. 
31. Machado DF, McLellan KCP, Murta-Nascimento C, Castanheira ERL, Almeida MAS. Abordagem da violência contra a mulher no ensino médico: um relato de experiência. Rev Bras Educ Med 2016; 40(3):511520.

32. D'Oliveira AFPL, Schraiber LB, Hanada H, Durand J. Atenção integral à saúde de mulheres em situação de violência de gênero - uma alternativa para a atenção primária em saúde. Cien Saude Colet 2009; 14(4):1037-1050.

33. Schraiber LB, D'Oliveira AFPL, Franca-Junior I, Pinho AA. Violência contra a mulher: estudo em uma unidade de atenção primária à saúde. Rev Saúde Pública 2002; 36(4):470-477.

34. Schraiber LB, D’Oliveira AFPL. Violência contra mulheres: interfaces com a saúde. Interface (Botucatu) 1999; 3(5):1-27.

35. Kiss LB, Schraiber LB. Temas médico-sociais e a intervenção em saúde: a violência contra mulheres no discurso dos profissionais. Cien Saude Colet 2011; 16(3):1943-1952.

36. Oliveira MLP, Meneghel SN, Bernardes JS. Modos de subjetivação de mulheres negras: efeitos da discriminação racial. Psicol Soc 2009; 21(2):266-274.

37. Schraiber LB, D’Oliveira AFPL, Portella AP, Menicucci E. Violência de gênero no campo da saúde coletiva: conquistas e desafios. Cien Saude Colet 2009; 14(4):1019-1027.

38. Granja E, Medrado B. Homens, violência de gênero e atenção integral em saúde. Psicol Soc 2009; 21(1):2534.

39. Brasil. Ministério do Desenvolvimento Social e Combate à Fome (MDS). Norma Operacional Básica do Sistema Único de Assistência Social - NOB - SUAS. Brasília: MDS; 2005.

40. Barufaldi LA, Souto RM CV, Correia RSDB, Montenegro MDMS, Pinto IV, Silva MMAD. Violência de gênero: comparação da mortalidade por agressão em mulheres com e sem notificação prévia de violência. Cien Saude Colet 2017; 22(9):2929-2938.

41. Mendes EV. As redes de atenção à saúde. Cien Saude Colet 2010; 15(5):2297-2305.

42. D'Oliveira AFPL, Schraiber LB. Mulheres em situação de violência: entre rotas críticas e redes intersetoriais de atenção. Rev Med (São Paulo) 2013; 92(2):134-140.

Artigo apresentado em 30/08/2017

Aprovado em 09/06/2018

Versão final apresentada em 11/06/2018 